\title{
Quantifying the variables affecting Indian medical tourism sector by graph theory and matrix approach
}

\author{
Vineet Jain $^{a^{*}}$ and Puneeta Ajmera ${ }^{b}$
}

${ }^{a}$ Department of Mechanical Engineering, Amity University Gurgaon, India

${ }^{b}$ Department of Hospital Administration, Amity Medical School, Amity University Haryana, India

CH R O N I C L E

Article history:

Received: November 26, 2017

Received in revised format: January 31,2018

Accepted: February 16, 2018

Available online:

February 16, 2018

Keywords:

Exploratory factor analysis

EFA

Medical Tourism

Graph theory and matrix ap-

proach

GTMA

Globalization

Liberalization

\section{A B S T R A C T}

\begin{abstract}
India has turned out to be one of the most favorite destinations for the patients who want to undertake cost effective medical care for various medical problems and who have infuriated from the long waiting lists for medical and diagnostic procedures in their home countries. This research aims to analyze different factors along with their intensity affecting medical tourism industry in a developing country like India so that managers and policymakers can take better decisions which will help in growth \& promotion of Indian health tourism market. The study has been done by performing a cross-sectional survey within major hospitals in India and exploratory factor analysis and graph theory and matrix approach have been used to evaluate the intensity of variables affecting Indian medical tourism sector. Nineteen variables have been identified through review of literature, and four factors have been extracted including cost, quality of treatment and care, availability of experts, competitive advantage and political, legal and visa related factors. With the understanding of the intensity of different variables suitable precautions can be taken by the healthcare managers so that these variables can be handled very carefully.
\end{abstract}

C 2018 by the authors; licensee Growing Science, Canada

\section{Introduction}

Medical tourism industry in India has been emerged as a multi-billion dollar industry and every year millions of patients from different countries travel to India to avail the state of art medical facilities and to enjoy the rich cultural heritage of the country. Globalization and liberalization of trade has led to the amalgamation of societies and economics all over the world leading to social, economic, technological, political and cultural interchanges which are made feasible by constant developments in communication, transportation, and infrastructure. Clinically excellent, well qualified and experienced healthcare professionals in Indian hospitals have achieved the trust of the medical tourists (Sharma, 2013). India has turned out to be one of the most favorite destinations for the patients who want to undertake cost effective medical care for various medical problems and who have infuriated from the long waiting

* Corresponding author. Tel.: +918901510570

E-mail address: vjdj2004@gmail.com (V. Jain) 
lists for medical and diagnostic procedures in their home country. Apart from the cheaper and affordable treatment there are some other factors also which are contributing towards growth in the number of medical tourists in India (Ajmera, 2017). Infrastructure of Indian hospitals, strong pharmacology sector, clinical excellence, Ayurveda and allopathic system of medicine, international accreditation like JCI to some Indian hospitals has proved to be a boon to healthcare sector in India. India offers approximately 20\% - 50\% cheaper treatment in comparison to countries like US, UK, Singapore and Thailand etc. Conventionally patients from underdeveloped or developing countries used to travel to the developed countries for availing medical treatment and seeking surgical procedures due to non-availability of the treatment in their host countries (Horowitz et al., 2007). But now scenario has changed. Recent drift is that people are moving from developed nations to developing nations for healthcare services due to cost factor as many developing countries are providing superior quality treatment at an affordable price, though the conventional trend is still continuing. Another reason for movement of patients is that medical procedures, like some fertility procedures, for example surrogacy, donor inseminations are not legal in their home country thereby causing the people to travel (Gahlinger, 2008). Besides the movement of patients there is movement of health professionals also which involves two aspects. One aspect is that health professionals move from developing or less developed countries to more developed countries for better employment opportunities. Second aspect is that rich countries tend to recruit experienced and well qualified healthcare professionals from poorer countries if they lack qualified professionals.

Due to the movement of healthcare services seekers and providers, medical tourism is getting more importance due to which contribution of private sector is increasing tremendously in providing healthcare services (Smith et al., 2009). This has increased the competition among different countries to become major key players. Major reason is the price differences between developed and developing countries. Healthcare expenses in developed countries are comparatively higher. Besides this ageing of populations in developed countries has also caused increase in demand for healthcare services and with the accessibility of latest, excellent quality and advanced clinical services at an affordable cost in developing nations, these countries are becoming hub for availing health procedures by patients of developed countries. In developed countries there are long waiting lists for medical procedures which is also causing inclination of patients towards developing countries. Due to development in information technology sector in India, a monumental revolution in health care industry has been observed. Also, there are world class, excellent academic and research institutions which produce clinically excellent medical professionals. It is expected that Indian Medical Tourism market will increase to 7-8 billion USD by 2020 from its present size of 3 billion USD. However because of huge competition in medical tourism sector, success can be achieved only by the combined endeavors by different key players in the market through the development and implementation of proper short term and long term strategies. Rich cultural heritage of India, various traditions and lifestyles, Ayurveda and yoga, beautiful beaches and wildlife parks and sanctuaries in India attract international patients apart from medical treatment.

There are many variables which affect Indian medical tourism sector. In this paper these variables have been evaluated by exploratory (EFA) and quantified by GTMA.

The objectives of present research are:

- To explore the variables which affect the Indian medical tourism sector.

- To identify the factors/dimensions affecting the Indian medical tourism sector.

- To evaluate the intensity of variables affecting Indian Medical Tourism sector by GTMA.

\section{Literature review}

Taking into account review of literature and consultation with the experts in the healthcare industry and the academia, 19 variables were extracted. These variables along with their references are given below in Table 1. 
Table 1

Indian Medical Tourism variables and their references

\begin{tabular}{cll}
\hline Sr No. & & \multicolumn{1}{c}{ Variable Name } \\
\hline 1 & Professionalism in management of hospitals & Glickman et al. (2007) \\
2 & Competence of doctors and staff & Glickman et al. (2007) \\
3 & Clinical excellence & Debata et al. (2013) \\
4 & Pharmacology sector & Horowitz et al. (2007) \\
5 & Effective Human resource pool & Debata et al. (2013) \\
6 & Facilitation and care & Ajmera et al. (2015) \\
7 & Interpreter facility & Ajmera et al. (2015) \\
8 & Dietary services & Sharma et al. (1999) \\
9 & Infrastructure of Indian hospitals & Debata et al. (2013) \\
10 & Medico legal security for medical tourists & Gupta et al. (2017) \\
11 & Insurance coverage & Gupta et al. (2017) \\
12 & Visa related issues & Expert opinion \\
13 & Efficient information system & Berg (1999) \\
14 & Coordination between healthcare \& tourism sector & Gupta et al. (2017) \\
15 & Transplantation law & Debata et al. (2013) and Acharya (1994) \\
16 & Cost of medical and diagnostic procedures & Horowitz et al. (2007) \\
17 & National healthcare policy of India & Bhatia \& Cleland (2001) \\
18 & Marketing strategies & Debata et al. (2011) \\
19 & Global competition & Cohen (2010) \\
\hline
\end{tabular}

Factor analysis is a multidimensional statistical approach which was used primarily in behavioral and social studies, psychology, education, and other fields of applied sciences dealing with huge amount of data, however during the past two decades it has been commonly used in the health care sector as well. It is used for reduction of data, development of various measurement scales, examining relationships between different variables, analyzing multicollinerity between variables and evaluating the construct validity evidence of scales. (Lozeron \& Victoria-Feser, 2010; Thompson, 2007). Factor analysis reduces a huge quantity of observed variables into lesser number of variables which are known as factors through correlations among the observed variables. In this technique factors which are also referred to as latent variables explain how different items or the observed variables are dependent upon each other and if the latent variables are fixed observed variables are independent. Factor analysis is categorized as exploratory (EFA) and confirmatory (CFA). Aim of Exploratory Factor Analysis is to explore a smaller and limited number of variables which are responsible for causing observed variance and covariance in the sample. It depends upon the researcher that how many factors should be retained taking into account both statistical and interpretational criteria (Fabrigar et al., 1999; MacCallum et al., 1999). Therefore, EFA is performed to identify the dimensions of a measurement scale by multivariate data analysis. SPSS version 20 has been used for exploratory factor analysis (EFA) to obtain dimensions from the variables which can be grouped (Jain \& Raj, 2013). The fundamental assumption of EFA is that there are k common 'latent' factors to be identified in the dataset, and the aim is to explore the least number of common factors considering the correlations among them (McDonald \& Ho, 2002). The dependent variables are referred as 'surface attributes' and the underlying variables as 'internal attributes. The factors which affect more than one of the surface attributes are common factors and the factors which affect only a particular variable are specific factors. This technique is most suitable in case of multivariate data which is distributed normally. The main objective of EFA is to explore the number of factors/dimensions, determine the variables that account for poor factor loading and to explore the factors that are badly measured in the research.

GTMA is a methodical and rational approach which is used in different areas. Digraph is dependent on the structure of the system and also is flexible so that changes can be analyzed. The traditional methods of representation such as flow-charts, block diagrams and cause and effect diagrams are not good in showing relationships among different variables and therefore they are very difficult to be analyzed, 
processed and written mathematically (Raj \& Attri, 2010). GTMA has an advantage above these traditional techniques. The important feature is that this approach provides a single mathematical index and converts qualitative values into quantitative values.

GTMA applications found in literature are presented in Table 2.

\section{Table 2}

GTMA applications found in literature.

\begin{tabular}{lll}
\hline Sr. No. & Name of the authors (year) & Application \\
\hline 1 & Kumar et al. (2017) & To fix the agility index of an automobile organization \\
2 & Jain \& Raj (2016) & Analysis for performance variables \\
3 & Lanjewar et al. (2016) & Evaluation and selection of energy technologies \\
4 & Jain \& Raj (2015) & Analysis for flexibility variables \\
5 & Jain \& Raj (2014) & Analysis for productivity variables \\
6 & Malhotra et al. (2012) & Evaluation of Barriers of RMS \\
7 & Saha \& Grover (2011) & Critical factors of website perform \\
8 & Raj et al. (2010) & Barriers in the FMSs \\
9 & Dou et al. (2009) & Optimize single-product flow-line \\
10 & Rao \& Padmanabhan (2007) & Rapid prototyping process selection \\
11 & Rao (2006) & Material selection model \\
12 & Garg et al. (2006) & Selection of power plants \\
13 & Grover et al. (2004) & TQM evaluation of an industry \\
14 & Gandhi \& Agrawal (1992) & FMEA diagraph and matrix approach \\
15 & Hammouche \& Webster (1985) & Layout problem \\
\hline
\end{tabular}

\section{Methodology}

For achieving the objectives of present work, firstly a questionnaire based survey has been conducted, Exploratory Factor Analysis is applied and later on GTMA has been used.

\subsection{Questionnaire based survey}

The questionnaire was constructed using a five-point Likert scale and administered to medical tourists who have come to Indian hospitals from different countries for availing medical treatments and were requested to mark the significance of 19 identified variables. One corresponds to 'very low' and 5 correspond to 'very high' in Likert scale. Out of 470 questionnaires 350 correctly completed questionnaires were considered thereby giving a response rate of $74 \%$, that is good for these types of surveys (Malhotra \& Grover, 1998).

\subsection{Exploratory Factor Analysis}

EFA has been performed to recognize the dimensions of Indian medical tourism sector. The procedure is given below (Jain \& Raj, 2013):

1. Data collection and exploration

The relevant variables were chosen by reviewing the literature thoroughly and opinions of experts from the healthcare sector. A questionnaire was framed and a survey was conducted to collect data.

2. Test the Internal Reliability Internal consistency was calculated with Cronbach's alpha with the help of SPSS software version 20. Cronbach's Alpha value more than 0.7 is considered to be ideal.

3. Test the Sampling Adequacy 
Sampling adequacy is tested by two measures:

(a) Kaiser- Meyer-Olkin (KMO-test) measure of sampling adequacy is used to determine if factor analysis is appropriate or not, is performed to check the sample adequacy. Factor analysis is considered to be suitable if the value of KMO lies between 0.5 and 1.0. If the value is less than 0.5 , it indicates that factor analysis is not fit for data (Kaiser, 1974).

(b) Bartlett's test of sphericity is used to test the hypothesis that there is no correlation between the variables. Values of level of significance less than 0.05 show that variables possess important relationships among them and if the value is greater than 0.10 , it shows that data is not suitable to run factor analysis (Jain \& Raj, 2013).

\section{Initial Extraction and select the variables to retain}

Communalities are found for initial extraction which indicates the amount of each variable variance which is accounted for. Values of communalities lie between 0 and 1. Lower values (less than 0.5) depict that variable is not suitable for the factor analysis which means variance is unexplained by the factors extracted and should be excluded from the analysis. High values (more than 0.5 ) indicate that the factors extracted account for most of the variance in the variables.

\section{Extraction of Initial Factors with Principal Components Analysis)}

(a) According to Kaiser's criterion, factors with an Eigenvalue more than one are considered as common factors (Nunnally, 1978).

(b) A solution which explains the most variance (50-75\%) with minimum factors is a good factor solution.

(c) A scree plot is drawn where an imaginary line joining the markers for consecutive factors is drawn from top left to the bottom right of the graph. Also there is a point in the graph above which factors explain more variance and below which the factors explain relatively little variance and this point is considered to be an "elbow" in the plot. Factors above the elbow are retained and those below the elbow are rejected (Cattell, 1966).

6. Select the number of factors which are to be retained.

7. Component Matrix is rotated with Varimax Kaiser Normalization.

8. If Changes like drop items or include items are required, they should be decided and incorporated.

9. Dimensions are identified.

\subsection{Graph theory and matrix approach (GTMA)}

In this research, this approach has been used in identifying the intensity of variables affecting the Indian medical tourism sector taking into consideration the degree of relationships among various variables. The network depicting this flexibility and relationships is referred to as the graph representation. The interactions can be classified as direction-dependent or independent. If the interactions are directionindependent, an undirected graph representation is taken and if these interactions are direction-dependent, it is known as a digraph representation (Jain \& Raj, 2015). The aim of present work is to correlate these four dimensions, quantify them depending on their variables and find the interdependencies of these four dimensions with the help of GTMA. Various steps of this approach are as under:

1. Digraph representation

2. Matrix representation

3. Permanent function representation. 


\subsubsection{Digraph representation}

This is done to depict the factors and their mutual dependence in the form of nodes and edges. In case of an undirected graph, direction is not provided to the edges while in case of digraphs direction is allocated to the edges. A node $n_{i}$ depicts the $i^{\text {th }}$ factor and the edges depict the interdependence among the factors. The number of nodes is equal to the number of factors. Draw a directed arrow from node $i$ to node $\mathrm{j}$ if node $i$ is relatively important over node $j$ i.e. $\mathrm{f}_{\mathrm{ij}}$ and vice versa i.e., $\mathrm{f}_{\mathrm{ji}}$. To develop digraph of the factors affecting Indian medical tourism sector, the four factors are taken into account and depicted by four nodes in the digraph as presented in Fig. 1. Depending upon the interdependence of these factors which are identified with the guidance of experts from healthcare sector, the directed edges are drawn and the relationships among them are then represented with the help of structural self-interaction matrix (SSIM).

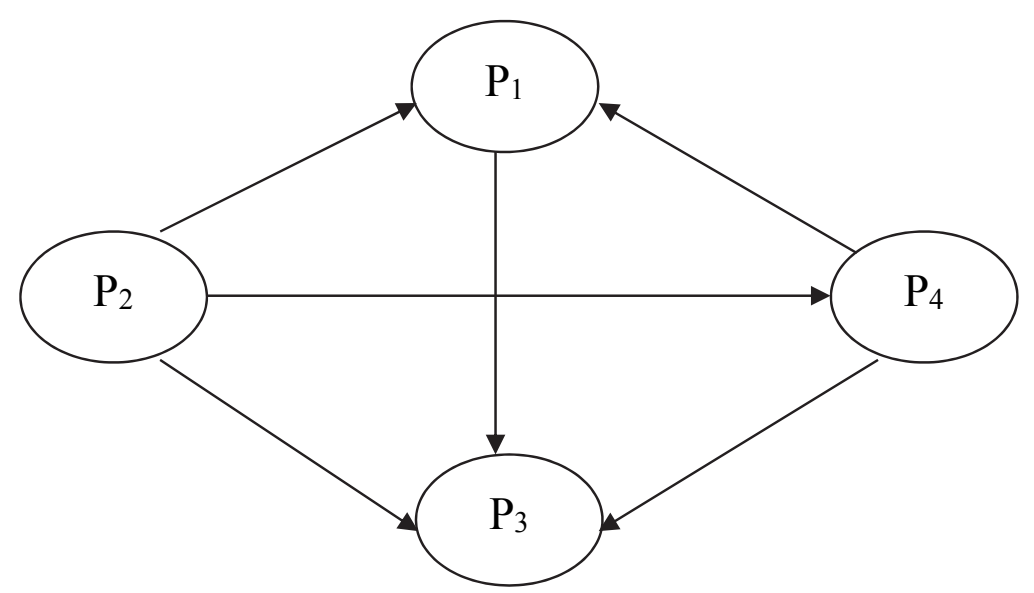

Fig. 1. Medical tourism factor digraph

The symbolic representation to assign the direction of interaction between two variables ( $i$ and $j$ ) is given in Table 3 .

Table 3

Symbols used to assign the direction of the relationship between two variables ( $\mathrm{i}$ and $\mathrm{j}$ )

\begin{tabular}{ll}
$\mathrm{V}$ & if factor $i$ influence or reach to factor $j$ \\
$\mathrm{~A}$ & if factor $j$ reach to factor $i$ \\
$\mathrm{O}$ & if factor $i$ and $j$ are unrelated \\
$\mathrm{X}$ & if factor $i$ and $j$ reach to each other \\
\hline
\end{tabular}

Depending on the contextual relationship, the SSIM is drawn, and it is depicted in Table 4.

\section{Table 4}

Relation between variables

\begin{tabular}{llll}
\hline & 4 & 3 & 2 \\
1 & $\mathrm{~A}$ & $\mathrm{~V}$ & $\mathrm{~A}$ \\
2 & $\mathrm{~V}$ & $\mathrm{~V}$ & \\
3 & $\mathrm{~A}$ & & \\
\hline
\end{tabular}

\subsubsection{Matrix representation}

Matrix representation of factors affecting Indian medical tourism sector digraph provides one-to-one representation known as the relative importance matrix (RIM which is a binary matrix (fij), in which fij depicts the pertinent importance between variables $i$ and $j$ where, 
$\mathrm{f}_{\mathrm{ij}}=1$, if the $\mathrm{i}^{\text {th }}$ attribute is more important than $\mathrm{j}^{\text {th }}$ attribute

$=0$, otherwise (Rao, 2007).

If there are $\mathrm{M}$ numbers of contributing categories of factors along with interdependencies among them and there are no self-loops, then the digraph for Indian Medical tourism sector is written as:

$$
P=\left(\begin{array}{lllllll}
F_{1} & F_{2} & F_{3} & - & - & F_{M} & \text { Variables } \\
F_{1} & f_{12} & f_{13} & - & - & f_{1 M} \\
f_{21} & F_{2} & f_{23} & - & - & f_{2 M} & F_{1} \\
f_{31} & f_{32} & F_{3} & - & - & f_{3 M} \\
- & - & - & - & - & - & F_{3} \\
- & - & - & - & - & - & - \\
f_{M 1} & f_{M 2} & f_{M 3} & - & - & F_{M}
\end{array}\right) F_{M}
$$

\subsubsection{Permanent function representation}

If the labelling of nodes is changed both digraph and matrix representations also change. So they are not considered to be unique. To draw a special unique representation which is independent of labelling, a permanent function of the matrix is proposed which is a standard matrix function and is commonly used in combinatorial mathematics. Same procedure is followed for permanent function as is followed for its determinant. To calculate the determinants, a negative sign is inserted, but in the variable permanent function these negative signs are reduced by positive signs. The intensity function for matrix $\mathrm{P}^{*}$ is written as:

$$
\begin{aligned}
& \text { Per } \mathrm{P}^{*}=\prod_{i=4}^{4} F_{i}+\sum_{i} \sum_{j} \sum_{k} \sum_{l}\left(F_{i j} F_{j i}\right) F_{k} F_{l}+\sum_{i} \sum_{j} \sum_{k} \sum_{l}\left(F_{i j} F_{j k} F_{k i}+F_{i k} F_{k j} F_{j i}\right) F_{l} \\
& +\left\{\sum_{i} \sum_{j} \sum_{k} \sum_{l}\left(F_{i j} F_{j i}\right)\left(F_{k l} F_{l k}\right)+\sum_{i} \sum_{j} \sum_{k} \sum_{l}\left(F_{i j} F_{j k} F_{k l} F_{l i}\right)+\left(F_{i l} F_{l k} F_{k j} F_{j i}\right)\right\}
\end{aligned}
$$

The permanent function of the matrix is a mathematical expression in symbolic form. These terms are organized in groups and their physical importance is as under:

- Interactions among four main factors are represented in first grouping (i.e., $\mathrm{F}_{1} \mathrm{~F}_{2} \mathrm{~F}_{3} \mathrm{~F}_{4}$ ).

- There is no second grouping, because self-loop is absent in the digraph (i.e., $\mathrm{f}_{\mathrm{ij}} \mathrm{f}_{\mathrm{ji}}$ ).

- A set of three-element interdependence loop is represented by each term of the fourth grouping (i.e., $\mathrm{f}_{\mathrm{ij}} \mathrm{f}_{\mathrm{j} k} \mathrm{f}_{\mathrm{ki}}$ or $\mathrm{f}_{\mathrm{i}} \mathrm{kf} \mathrm{f}_{\mathrm{kj}} \mathrm{f}_{\mathrm{ji}}$ ).

- Terms arranged in two subgroups are present in fifth grouping. Two-element interdependence loops are present in the terms of the first subgroup (i.e., fijfji and fklflk).

- The terms of the second subgroup are a product of four-element interdependence loops (i.e., $f_{i j} f_{j k} f_{k 1} f_{l i}$ or $\left.f_{i j} f_{l k} f_{k j} f_{j i}\right)$.

\subsubsection{Indian Medical Tourism index}

The intensity of variables which affect Indian medical tourism sector can be defined as the inhibiting strength (i.e., overall impact) of all the factors affecting this sector. Therefore it is very difficult but useful to evaluate these factors and to find their impact. The permanent inhibiting function is presented here for the assessment of the intensity of variables due to the presence of four factors along with their interdependencies. 
The mathematical value of this matrix [equation (2)] is called the (IOF)IMT, which represents the index of Indian Medical tourism:

$(\mathrm{IOF})_{\mathrm{IMT}}=\operatorname{per}\left(\mathrm{F}^{*}\right)=$ Permanent function of Indian Medical

Tourism sector matrix

The (IOF) IMT value for various healthcare institutions may be calculated using the methodology stated in the present article and hence comparisons can be made among different organizations.

\section{Steps involved in GTMA process are given below}

1. Different variables that affect the Indian medical tourism market are classified into the main factors with the help of SPSS.

2. Taking into account their interdependencies, a digraph is drawn between the factors in which the nodes represent factors and the relationships among them are represented by the edges as depicted in Figure 1 and SSIM as shown in Table 3.

3. Depending upon the inheritances and interactions, a variable digraph of size $\mathrm{M} \times \mathrm{M}$ is developed, where elements at the diagonal represent attributes and the off diagonal elements represent their mutual relationships. This signifies digraph at each subsystem level. After this SSIM at each sub system level is developed.

4. Considering digraphs among the variables as described above, the variables' matrix is derived at the subsystem level where diagonal elements represent inheritances and the off diagonal elements represent their interrelationships.

5. With the expert opinion numerical values taken from Tables 5 and 6 are assigned for the inheritance of attributes and their relationships.

Table 5

The inheritance of Indian Medical Tourism variables

\begin{tabular}{ccc}
\hline S. No & Qualitative measure of IMT variables & Assigned value of IMT variables \\
\hline 1 & Exceptionally low 2 & 1 \\
2 & Extremely low & 2 \\
3 & Very low & 3 \\
4 & Below average & 4 \\
5 & Average & 5 \\
6 & Above average & 6 \\
7 & High & 7 \\
8 & Very high & 8 \\
9 & Extremely high & 9 \\
10 & Exceptionally high & 10 \\
\hline
\end{tabular}

Table 6

The values of interdependence of Indian Medical Tourism variables:

\begin{tabular}{ccc}
\hline S.No & Qualitative measure of interdependence of IMT variables & Assigned value (fij) \\
\hline 1 & Very strong & 5 \\
2 & String & 4 \\
3 & Medium & 3 \\
4 & Weak & 2 \\
5 & Very Weak & 1 \\
\hline
\end{tabular}

6. Write the value of a permanent function for sub-factor.

7. Process described in points 3 to 6 are repeated for every sub-factor.

8. Digraph and matrix for the factors affecting Indian medical tourism sector is developed at system level as described in Steps 2 and 3. 
9. At system level, the permanent value of each sub factor (as found in Step 7) gives inheritance of Indian Medical Tourism sector (diagonal elements). The numerical value of relationships among factors (off diagonal elements) is taken from Table 5 by taking expert opinion for suitable interpretation by experts. In this way a matrix is formed at the system level.

10. The value of a permanent function of the system for the factors affecting Indian medical tourism market is obtained.

\section{Evaluation of Variables by Exploratory Factor Analysis}

SPSS version 20 is used to perform EFA.

1. 19 variables were explored through review of literature and opinions of experts.

2. A structured questionnaire was to conduct a survey and data was collected. 300 participants from healthcare industry were contacted to collect data.

3. Reliability of the variables was confirmed with Cronbach's Alpha. The value of Cronbach's Alpha is 0.782 i.e. greater than 0.7 .

4. KMO and Bartlett's measure of specificity was performed, KMO Value is 0.831 , and the significance value is 0.000 . This shows that factor analysis can be run for the data.

5. The result of communalities in the analysis depicts that most of the variables have their communalities more than 0.5 .

6. Four components having an Eigen value more than one are extracted and accounts for the total variance 54.910. It is clear from the Scree plot that four components are extracted having significant loadings. Scree plot is shown in Figure 2.

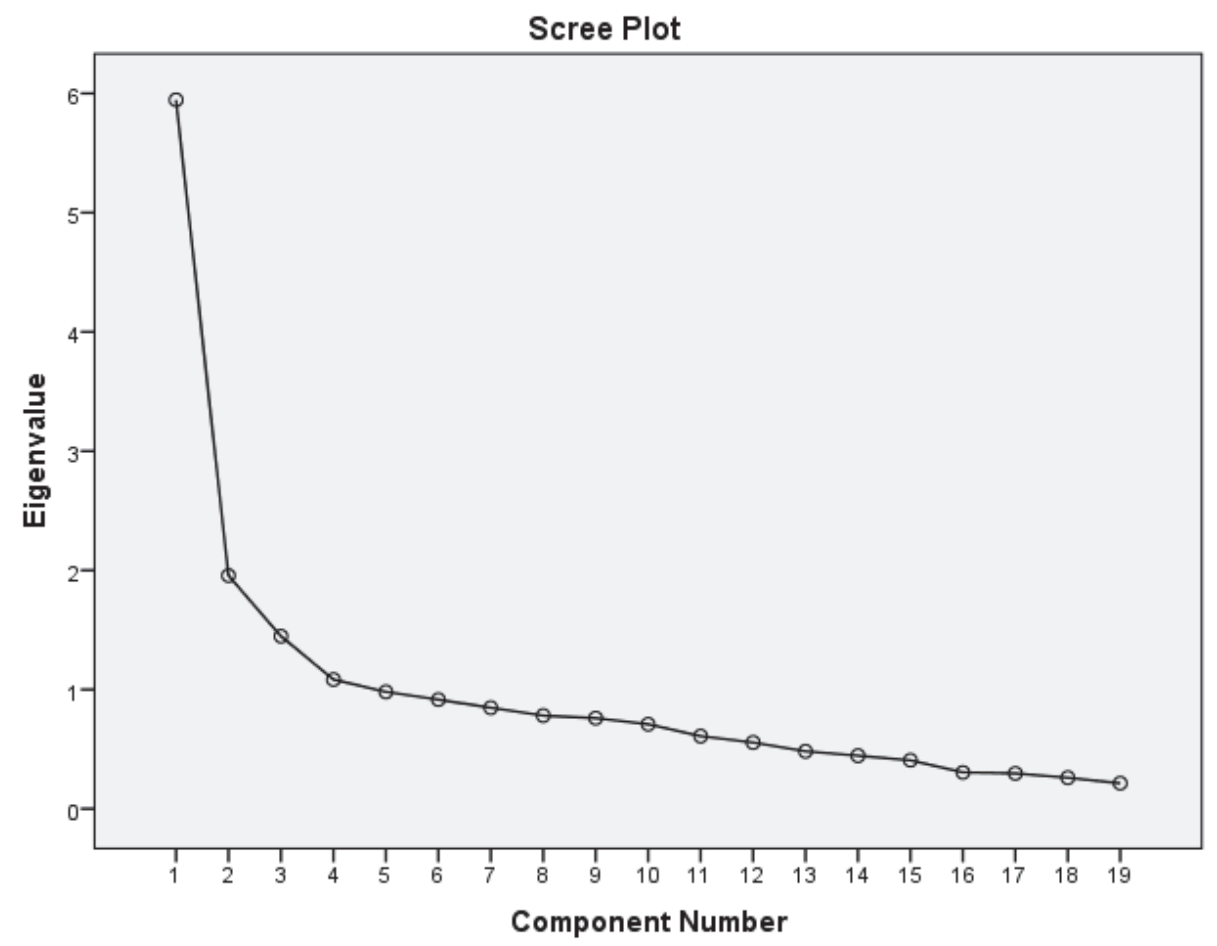

Fig. 2. Scree Plot

7. Since no change is detected, four components are considered after rotation of the component matrix with Varimax with Kaiser normalization.

8. As per the results of EFA, the factors were categorized into four dimensions named suitably and are depicted in Table 7. 


\section{Table 7}

Factors/Dimensions of Indian Medical Tourism sector

\begin{tabular}{|c|c|c|c|}
\hline S. No & Dimensions/Factors & Variables & Factor loading \\
\hline \multirow[t]{8}{*}{1} & \multirow{8}{*}{$\begin{array}{l}\text { Cost, quality of treatment } \\
\text { and care }\end{array}$} & Pharmacology sector & 0.571 \\
\hline & & Facilitation and care & 0.641 \\
\hline & & Interpreter facility & 0.580 \\
\hline & & Dietary services & 0.587 \\
\hline & & Infrastructure of Indian hospitals & 0.723 \\
\hline & & Insurance coverage & 0.494 \\
\hline & & Efficient information system & 0.566 \\
\hline & & $\begin{array}{l}\text { The cost of medical and diagnostic pro- } \\
\text { cedures }\end{array}$ & 0.727 \\
\hline \multirow[t]{3}{*}{2} & \multirow[t]{3}{*}{ Availability of experts } & Competence of doctors and staff & 0.803 \\
\hline & & Clinical excellence & 0.688 \\
\hline & & Effective Human Resource pool & 0.531 \\
\hline \multirow[t]{4}{*}{3} & \multirow[t]{4}{*}{ Competitive advantage } & $\begin{array}{l}\text { Professionalism in the management of } \\
\text { hospitals }\end{array}$ & 0.690 \\
\hline & & Coordination between healthcare \& & 0.593 \\
\hline & & tourism sector & 0.598 \\
\hline & & Global competition & \\
\hline \multirow[t]{5}{*}{4} & \multirow{5}{*}{$\begin{array}{l}\text { Political, legal and visa re- } \\
\text { lated factors }\end{array}$} & Medico-legal security for medical tour- & 0.646 \\
\hline & & ists & 0.626 \\
\hline & & Visa related issues & 0.517 \\
\hline & & Transplantation law & 0.738 \\
\hline & & $\begin{array}{l}\text { National healthcare policy of India } \\
\text { Marketing strategies }\end{array}$ & 0.648 \\
\hline
\end{tabular}

The four dimensions which have been identified are as under:

(a) Cost, quality of treatment and care

(b) Availability of experts

(c) Competitive advantage

(d) Political, legal and visa related factors

(a) Cost, quality of treatment and care

Cost of medical procedures in Indian hospitals is comparatively cheaper in comparison to developed countries like USA and UK. Infrastructure of Indian hospitals is at par to that of developed countries and therefore medical tourists select India as their favorable destination because of the efficient infrastructures and technology of Indian healthcare sector.

(b) Availability of experts

Highly competent, skilled and expert manpower in the hospitals in India is able to handle any type of medical complications. Indian nurses are considered to be the best in the world. Highly experienced and talented healthcare professionals, consisting of doctors, surgeons, nurses, technicians, medical coordinators, and dietary experts are working together to provide their services to the medical tourists with their expertise in conducting complicated operations and other clinical procedures.

(c) Competitive advantage

Professionalism in the management of hospitals in India and coordination with various travel agencies offer competitive advantage for Indian hospitals and achieved a global advantage. Hospitals contact 
these travel agencies and then send the patients to rehabilitate in a beautiful, calm and pleasing environment which help them in their speedy recovery.

(d) Political, legal and visa related factors

More participation by the government with strict policies and litigation is required to secure the international patients against malpractice, pre and post-operative complications and ethical issues as these factors play a key role in promoting medical tourism.

Depending upon the methodology discussed above, the intensity of variables affecting Indian medical tourism market can be analyzed.

\section{Evaluation of intensity of variables affecting Indian Medical Tourism Sector by GTMA}

The analysis is carried out in two steps. In the first step, Exploratory Factor Analysis is performed with the help of SPSS 20 for grouping the variables and in the second step the intensity of variables affecting Indian Medical Tourism Sector is evaluated with GTMA. Variables are analyzed in the following way:

1. Nineteen variables were explored through review of literature and opinion of experts. A survey using a structured questionnaire was conducted to collect data. Questionnaires were distributed to 300 subjects including doctors, nurses and other healthcare professionals dealing with international patients.

2. Cronbach's alpha's value is 0.782 indicating good internal consistency of variables.

3. The KMO value and Barlet Measure of Sphericity is 0.831 , and 0.000 respectively which shows that data is suitable to run factor analysis.

4. 19 variables are identified and four components are extracted having an eigenvalue more than one and explain the total variance 54.910 which is acceptable. Scree plot also shows that four components extracted, having a significant loading more than 0.30 .

5. Four components are included after rotation of the component matrix with Varimax with Kaiser Normalization as no change is observed.

6. A digraph is derived for these four factors after identification of four factors through EFA, as shown in Figure 1 and the SSIM developed as given in Table 2.

7. The digraphs for each category of factors (Figure 3-6) are developed taking into account the variables that affect the particular category of factors. The variables in the diagraph are represented by nodes and their mutual interaction is represented by different edges.

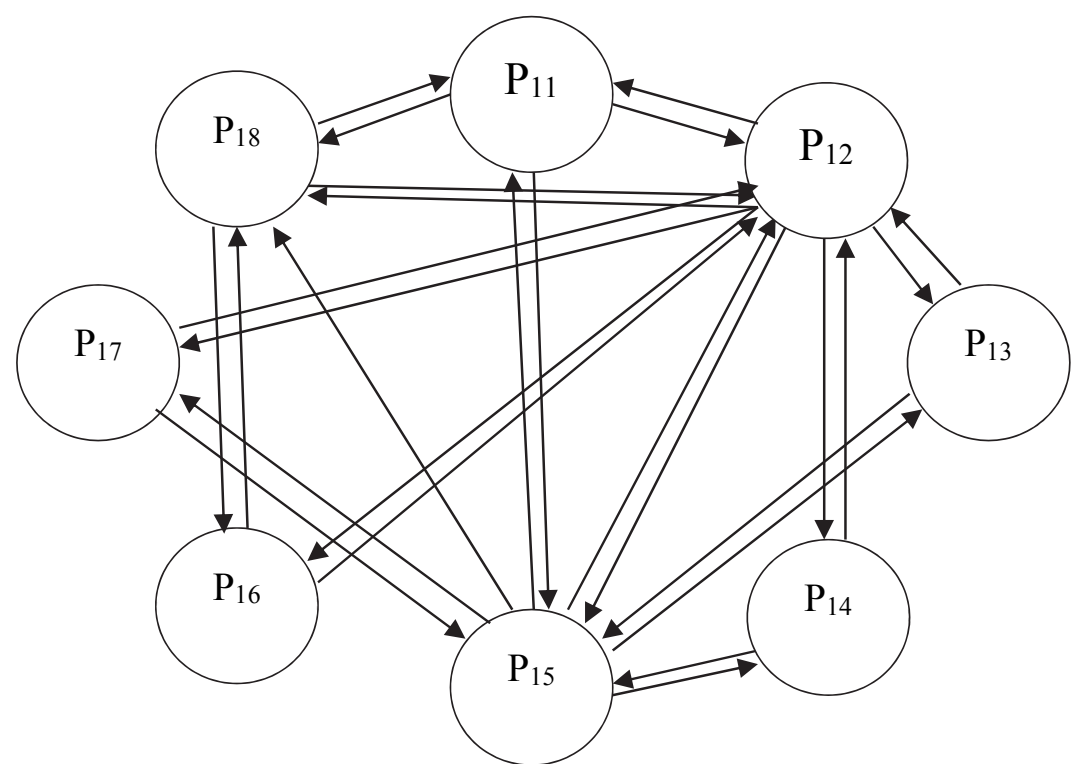

Fig. 3. Digraph for Cost quality of treatment and care 


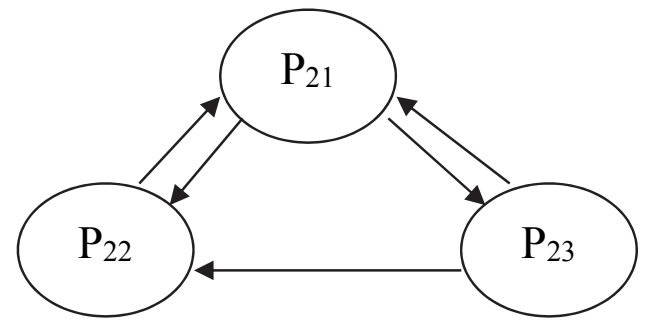

Fig. 4. Digraph for Avaliablity of Experts

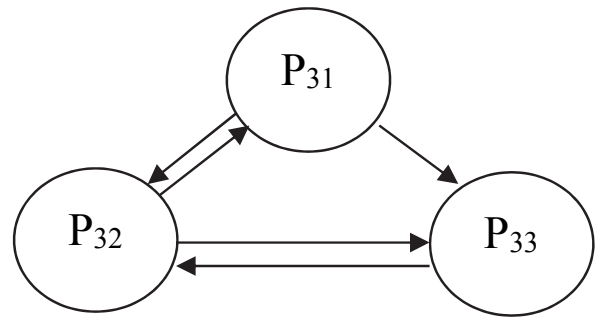

Fig. 5. Digraph for Competitive advantage

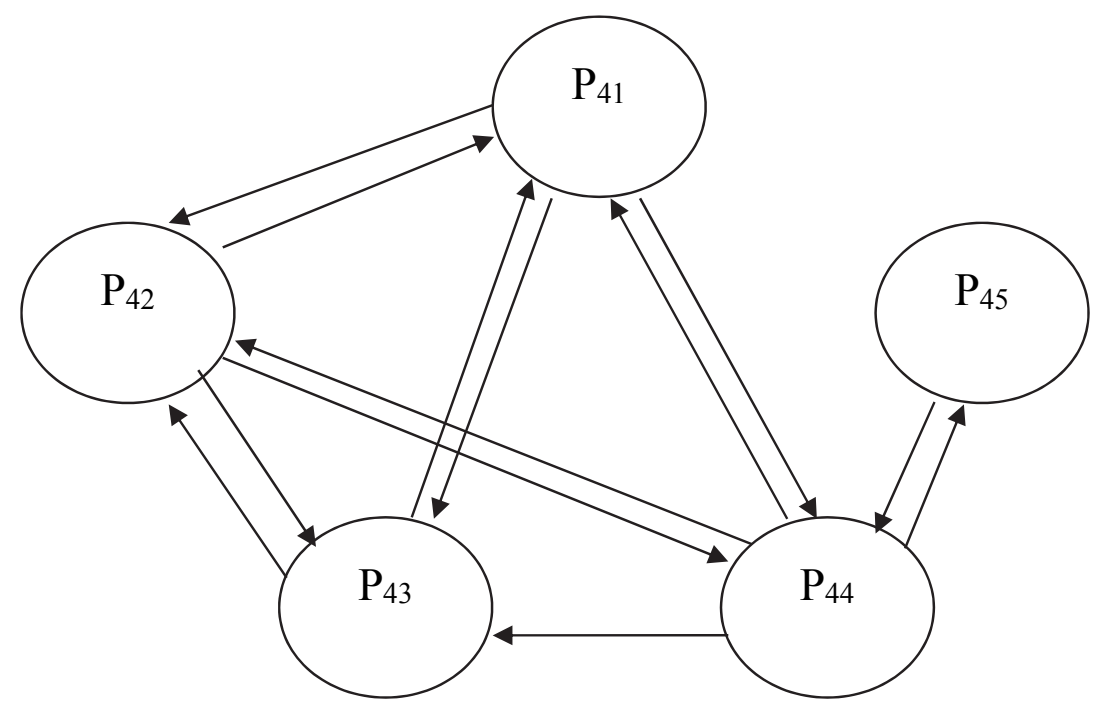

Fig. 6. Digraph for Political, Legal and Visa related factor

8. The inheritance of factors and their interdependencies after experts opinion as per Tables 4 and 5 and the matrix for each category is written as:

$$
\begin{aligned}
& \begin{array}{lllllllll}
F_{11} & F_{12} & F_{13} & F_{14} & F_{15} & F_{16} & F_{17} & F_{18} & \text { Variable }
\end{array} \\
& \left(\begin{array}{llllllll}
6 & 3 & 0 & 0 & 6 & 0 & 0 & 1 \\
1 & 7 & 4 & 4 & 5 & 3 & 3 & 2 \\
0 & 3 & 6 & 0 & 3 & 0 & 0 & F_{11} \\
F_{12}
\end{array}\right.
\end{aligned}
$$

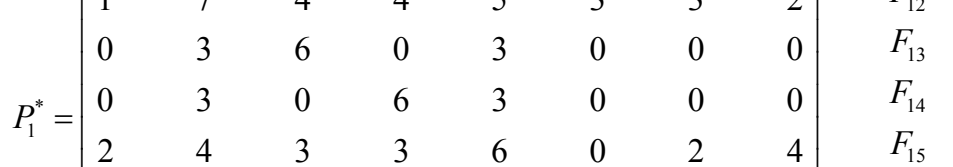

$$
\begin{aligned}
& \begin{array}{llllllll}
0 & 3 & 0 & 0 & 0 & 6 & 0 & 3 \\
0 & 3 & 0 & 0 & 3 & 0 & 6 & 0 \\
1 & 3 & 0 & 0 & 0 & 3 & 0 & F_{16}
\end{array} \\
& \left(\begin{array}{llllllll}
0 & 3 & 0 & 0 & 3 & 0 & 6 & 0 \\
1 & 3 & 0 & 0 & 0 & 3 & 0 & 8
\end{array}\right) \quad \begin{array}{l}
F_{17} \\
F_{18}
\end{array} \\
& F_{21} \quad F_{22} \quad F_{23} \quad \text { variable } \\
& P_{2}^{*}=\left(\begin{array}{ccc}
8 & 5 & 1 \\
4 & 6 & 0 \\
4 & 4 & 7
\end{array}\right) \quad \begin{array}{l}
F_{21} \\
F_{22} \\
F_{23}
\end{array}
\end{aligned}
$$




$$
\begin{aligned}
& \text { V. Jain and P. Ajmera / Management Science Letters } 8 \text { (2018) }
\end{aligned}
$$

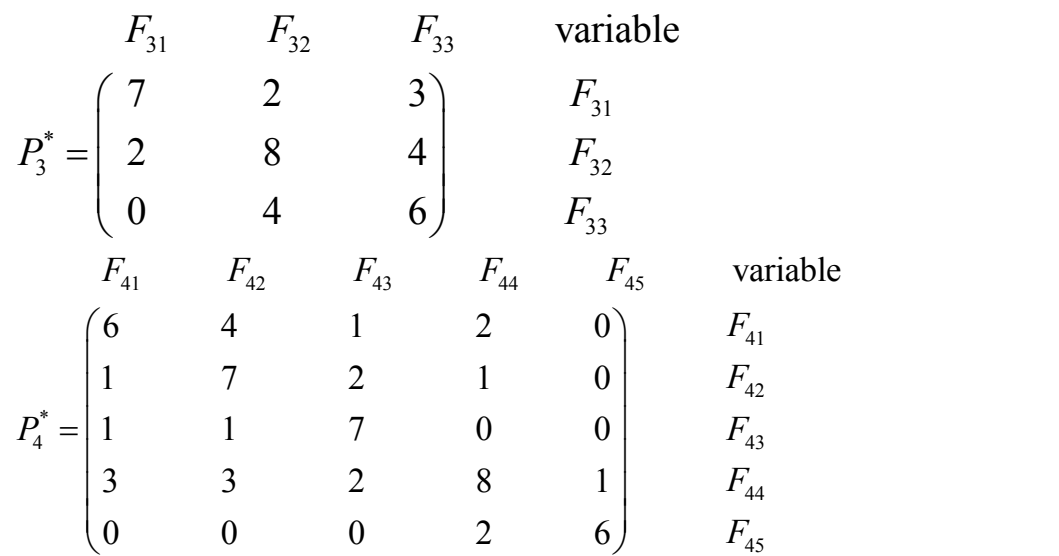

9. In this research, the value of the permanent function for each category is calculated by a computer program which is developed in $\mathrm{C}++$ language. The value of permanent function for each category is as follows:

Per $\mathrm{P}_{1}{ }^{*}=23307264$, Per $\mathrm{P}_{2}{ }^{*}=516$, Per $\mathrm{P}_{3}{ }^{*}=496$ and Per $\mathrm{P}_{4}{ }^{*}=20680$

10. The matrix at the system level is derived according to equation (2). In this matrix, the values of the diagonal elements are taken from the sub-system level:

$\mathrm{P} 1=\operatorname{Per} \mathrm{P}_{1}{ }^{*}=23307264, \mathrm{P} 2=\operatorname{Per} \mathrm{P}_{2}{ }^{*}=516, \mathrm{P} 3=\mathrm{Per}_{3}{ }^{*}=496$ and $\mathrm{P}_{4}={\mathrm{Per} \mathrm{P}_{4}}^{*}=20680$

$$
P^{*}=\left(\begin{array}{ccccc}
F_{1} & F_{2} & F_{3} & F_{4} & \text { variable } \\
23307264 & 0 & 5 & 0 \\
4 & 516 & 4 & 2 & F_{1} \\
0 & 0 & 496 & 0 \\
2 & 0 & 2 & 20680
\end{array}\right) F_{2} F_{3} F_{4}
$$

12. Value of permanent function of the system is analyzed. The value of Per $\mathrm{P}^{*}$ at the system level of above matrix is $123 \times 10^{15}$, which shows that the index for the variables. Hypothetical best and hypothetical worst value of the Indian medical tourism index is obtained. The index is at its best when the inheritance of all its factors is at its best. At the subsystem level, maximum value of Per $\mathrm{P}_{1} *$ is obtained when inheritance of all the sub-factors are maximized, i.e., value taken from Table 4 is 10 . Thus, matrix for this category is rewritten as:

$$
P_{1}^{*}=\left(\begin{array}{ccccccccc}
F_{11} & F_{12} & F_{13} & F_{14} & F_{15} & F_{16} & F_{17} & F_{18} & \multicolumn{2}{l}{\text { Variable }} \\
10 & 3 & 0 & 0 & 6 & 0 & 0 & 1 \\
1 & 10 & 4 & 4 & 5 & 3 & 3 & 2 \\
0 & 3 & 10 & 0 & 3 & 0 & 0 & 0 & F_{11} \\
F_{12} \\
0 & 3 & 0 & 10 & 3 & 0 & 0 & 0 \\
2 & 4 & 3 & 3 & 10 & 0 & 2 & 4 \\
0 & 3 & 0 & 0 & 0 & 10 & 0 & 3 \\
0 & 3 & 0 & 0 & 3 & 0 & 10 & 0 \\
F_{14} \\
F_{15} \\
F_{16} \\
F_{17} \\
3 & 3 & 0 & 0 & 0 & 3 & 0 & 10
\end{array}\right) F_{18}
$$

The maximum value of Per $\mathrm{P}_{1}{ }^{*}=$ for the first category is 313212000 . Similarly, the medical tourism factor at its worst when the inheritance of all its factors and variables is at its worst. This is the case when inheritance of the entire variables is minimum, i.e., value taken from Table 5 is 1 . Thus, medical tourism factor matrix for this category is rewritten as: 


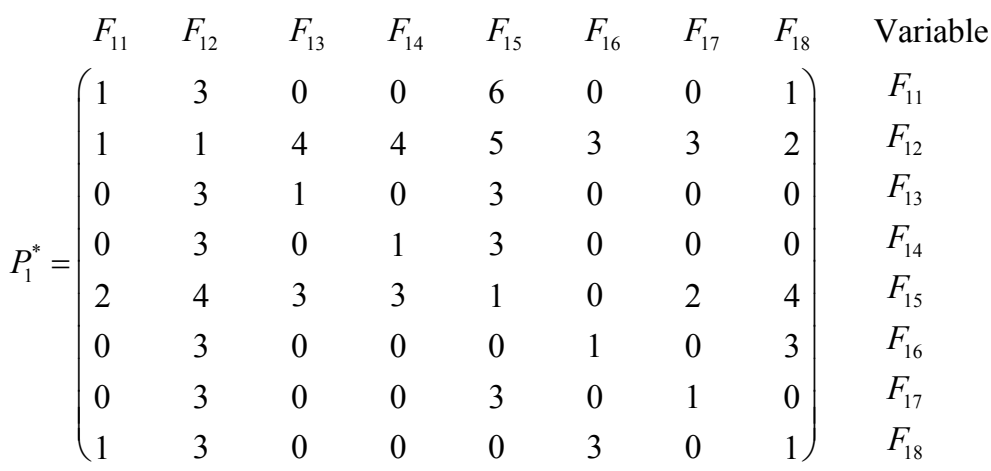

The minimum value of $\operatorname{Per} \mathrm{P}_{1}{ }^{*}=$ for the first category is 33834 . Evaluation of maximum and minimum values for each subsystem is done and different values of permanent of subsystem matrices are depicted in Table 8. Maximum values of all subsystems are considered to evaluate the maximum value of the index at system level. Similarly, minimum values of all the subsystems are considered to evaluate the minimum value of subsystem. The value of the IMT index is indicated by the value of per P. Thus, the maximum and minimum value of IMT index indicates the range within which it can vary. This range can be used by the experts to decide a threshold value for Indian medical tourism sector.

Table 8

The maximum and minimum values of the permanent function

\begin{tabular}{llll}
\hline $\begin{array}{l}\text { Permanent function at the } \\
\text { Subsystem/system level }\end{array}$ & Maximum value & Minimum value & Current value \\
\hline Per $P_{1}^{*}$ & 313212000 & 33834 & 23307264 \\
Per $P_{2}^{*}$ & 1256 & 41 & 516 \\
Per $P_{3}^{*}$ & 1224 & 45 & \\
Per $P_{4}^{*}$ & 112474 & 112 & \\
Per $P^{*}$ & $579 \times 10^{17}$ & $699 \times 10^{7}$ & \\
\hline
\end{tabular}

\section{Discussion and conclusions}

This research has provided a deeper understanding of the evaluation of variables affecting the Indian medical tourism sector in the healthcare industry. From the nineteen identified variables, four components (Cost, quality of treatment and care, Availability of experts, Competitive advantage and Political, legal and visa related factors) were extracted having an eigenvalue more than one and explained the total variance 54.910 and as per the scree plot, which had a significant loading greater than 0.30 . It is very much evident from the data analysis that cost, quality of treatment and care was the most important factor for Indian medical tourism industry. So more emphasis should be laid on this factor for gaining competitive advantage. Data analysis results were investigated to examine the intensity of variables affecting Indian medical tourism sector by GTMA which helps in the calculation of intensity of various variables. Results of GTMA approach also depict that cost, quality of treatment and care had the maximum intensity as shown in Table 8 . Therefore, with the understanding of the intensity of different variables, better decisions and suitable precautions can be taken by the healthcare managers so that these variables can be handled very carefully. Results of present work also show that there is a significant difference between current value and the maximum value of permanent function at the subsystem and system level. So efforts must be done by Indian hospitals to achieve the maximum value. This research aims to improve the system as the current value of Indian medical tourism index is $123 \times 10^{15}$ which is less than the maximum value of $579 \times 10^{17}$ thereby showing the scope of improvement in the variables affecting Indian medical tourism. Table 8 shows the results of system or sub-system levels. 


\section{Relevance of research to healthcare industry}

Medical tourism facilitates the movement of patients, healthcare service providers and skilled professionals and encourages trade in healthcare services across borders. Another aspect is that it is faced by many challenges like ethical and legal issues and public private sector health inequity. This research intends to analyze the different factors along with their intensity affecting medical tourism industry in a developing country like India so that managers and policymakers can analyze the strength of these variables and take better decisions which will help in growth and promotion of Indian health tourism market.

\section{References}

Acharya, V. N. (1994). Status of renal transplant in India--May 1994. Journal of Postgraduate Medicine, 40(3), 158.

Ajmera, P. (2017). Ranking the strategies for Indian medical tourism sector through the integration of SWOT analysis and TOPSIS method. International Journal of Health Care Quality Assurance, 30(8), 668-679.

Ajmera, P., Singh, M., \& Satia, H. (2015). Prioritization of Strengths, Weaknsses, Opportunities and Threats of Indian Medical Tourism Sector Using Integrated SWOT AHP Analysis. International Journal of Innovative Research in Science, Engineering and Technology, 4, 3665-3673.

Berg, M. (1999). Patient care information systems and health care work: a sociotechnical approach. International Journal of Medical Informatics, 55(2), 87-101.

Bhatia, J. C., \& Cleland, J. (2001). Health-care seeking and expenditure by young Indian mothers in the public and private sectors. Health Policy and Planning, 16(1), 55-61.

Cattell, R. B. (1966). The scree test for the number of factors. Multivariate Behavioral Research, 1(2), 245-276.

Cohen, I. G. (2010). Medical tourism: The view from ten thousand feet. Hastings Center Report, 40(2), 11-12.

Debata, B. R., Patnaik, B., Mahapatra, S., \& Sreekumar. (2011). Development of an instrument for measuring service quality of medical tourism in India. International Journal of Indian Culture and Business Management, 4(6), 589-608.

Debata, B. R., Sree, K., Patnaik, B., \& Mahapatra, S. S. (2013). Evaluating medical tourism enablers with interpretive structural modeling. Benchmarking: An International Journal, 20(6), 716-743.

Dou, J., Dai, X., \& Meng, Z. (2009). Graph theory-based approach to optimize single-product flow-line configurations of RMS. The International Journal of Advanced Manufacturing Technology, 41(9-10), 916931.

Fabrigar, L. R., Wegener, D. T., MacCallum, R. C., \& Strahan, E. J. (1999). Evaluating the use of exploratory factor analysis in psychological research. Psychological methods, 4(3), 272.

Gahlinger, P. (2008). The Medical Tourism Travel Guide: Your Complete Reference to Top-quality, Low-cost Dental, Cosmetic, Medical Care \& Surgery Overseas. North Branch, MN: Sunrise River Press.

Gandhi, O., \& Agrawal, V. (1992). FMEA - A diagraph and matrix approach. Reliability Engineering \& System Safety, 35(2), 147-158.

Garg, R., Agrawal, V., \& Gupta, V. (2006). Selection of power plants by evaluation and comparison using graph theoretical methodology. International Journal of Electrical Power \& Energy Systems, 28(6), 429-435.

Glickman, S. W., Baggett, K. A., Krubert, C. G., Peterson, E. D., \& Schulman, K. A. (2007). Promoting quality: the health-care organization from a management perspective. International Journal for Quality in Health Care, 19(6), 341-348.

Grover, S., Agrawal, V., \& Khan, I. (2004). A digraph approach to TQM evaluation of an industry. International Journal of Production Research, 42(19), 4031-4053.

Gupta, M. K., Rajachar, V., \& Prabha, C. (2017). Medical tourism: a new growth factor for Indian healthcare industry. International Journal of Research in Medical Sciences, 3(9), 2161-2163.

Hammouche, A., \& Webster, D. (1985). Evaluation of an application of graph theory to the layout problem. International Journal of Production Research, 23(5), 987-1000.

Horowitz, M. D., Rosensweig, J. A., \& Jones, C. A. (2007). Medical tourism: globalization of the healthcare marketplace. MedGenMed, 9(4), 33.

Jain, V., \& Raj, T. (2013). Evaluating the Variables Affecting Flexibility in FMS by Exploratory and Confirmatory Factor Analysis. Global Journal of Flexible Systems Management, 14(4), 181-193. doi: 10.1007/s40171-013-0042-9 
Jain, V., \& Raj, T. (2014). Modelling and analysis of FMS productivity variables by ISM, SEM and GTMA approach. Frontiers of Mechanical Engineering, 9(3), 218-232.

Jain, V., \& Raj, T. (2015). Evaluating the intensity of variables affecting flexibility in FMS by graph theory and matrix approach. International Journal of Industrial and Systems Engineering, 19(2), 137-154. doi: 10.1504/IJISE.2015.067245

Jain, V., \& Raj, T. (2016). Modeling and analysis of FMS performance variables by ISM, SEM and GTMA approach. International Journal of Production Economics, 171(1), 84-96.

Kaiser, H. F. (1974). An index of factorial simplicity. Psychometrika, 39(1), 31-36.

Kumar, P., Singh, R. K., \& Kumar, R. (2017). An integrated framework of interpretive structural modeling and graph theory matrix approach to fix the agility index of an automobile manufacturing organization. International Journal of System Assurance Engineering and Management, 8(1), 342-352.

Lanjewar, P., Rao, R., Kale, A., Taler, J., \& Ocłoń, P. (2016). Evaluation and selection of energy technologies using an integrated graph theory and analytic hierarchy process methods. Decision Science Letters, 5(2), 237348.

Lozeron, E. D., \& Victoria-Feser, M.-P. (2010). Robust estimation of constrained covariance matrices for confirmatory factor analysis. Computational Statistics \& Data Analysis, 54(12), 3020-3032.

MacCallum, R. C., Widaman, K. F., Zhang, S., \& Hong, S. (1999). Sample size in factor analysis. Psychological methods, 4(1), 84.

Malhotra, M. K., \& Grover, V. (1998). An assessment of survey research in POM: from constructs to theory. Journal of operations management, 16(4), 407-425.

Malhotra, V., Raj, T., \& Arora, A. (2012). Evaluation of Barriers Affecting Reconfigurable Manufacturing Systems with Graph Theory and Matrix Approach. Materials and Manufacturing Processes, 27(1), 88-94.

McDonald, R. P., \& Ho, M.-H. R. (2002). Principles and practice in reporting structural equation analyses. Psychological methods, 7(1), 64.

Nunnally, J. C. (1978). Psychometric Theory (2nd ed.). New York: Tata McGraw-Hill Education.

Raj, T., \& Attri, R. (2010). Quantifying barriers to implementing total quality management (TQM). European Journal of Industrial Engineering, 4(3), 308-335.

Raj, T., Shankar, R., Suhaib, M., \& Khan, R. (2010). A graph-theoretic approach to evaluate the intensity of barriers in the implementation of FMSs. International Journal of Services and Operations Management, 7(1), 24-52.

Rao, R. V. (2006). A material selection model using graph theory and matrix approach. Materials Science and Engineering: A, 431(1), 248-255.

Rao, R. V. (2007). Decision making in the manufacturing environment: using graph theory and fuzzy multiple attribute decision making methods. London: Springer.

Rao, R. V., \& Padmanabhan, K. (2007). Rapid prototyping process selection using graph theory and matrix approach. Journal of Materials Processing Technology, 194(1), 81-88.

Saha, R., \& Grover, S. (2011). Critical factors of website performance: a graph theoretic approach. International Journal of Web Science, 1(1), 54-98.

Sharma, A. (2013). Medical tourism: emerging challenges and future prospects. International Journal of Business and Management Invention, 2(1), 21-29.

Sharma, M., Rao, M., Jacob, S., \& Jacob, C. (1999). A dietary survey in Indian hemodialysis patients. Journal of Renal Nutrition, 9(1), 21-25.

Smith, R. D., Chanda, R., \& Tangcharoensathien, V. (2009). Trade in health-related services. The Lancet, 373(9663), 593-601.

Thompson, B. (2007). Exploratory and confirmatory factor analysis: Understanding concepts and applications. Applied Psychological Measurement, 31(3), 245-248.

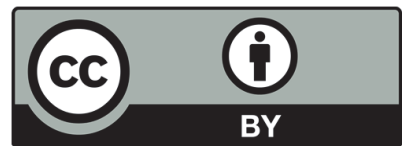

(C) 2018 by the authors; licensee Growing Science, Canada. This is an open access article distributed under the terms and conditions of the Creative Commons Attribution (CC-BY) license (http://creativecommons.org/licenses/by/4.0/). 